\title{
La acción sindical en la Argentina contemporánea desde la perspectiva del nuevo institucionalismo: un análisis de sus alcances y limitaciones*
}

\author{
Union Action in Contemporary Argentina from \\ the Perspective of New Institutionalism: \\ An Analysis of its Scope and Limitations
}

Esteban Iglesias $^{* *}$

Recibido: 01/09/2014

Aprobado: 03/06/2015

Disponible en línea: 30/11/2015

\section{Resumen}

El propósito del trabajo es analizar los alcances y limitaciones del enfoque neo-institucional en lo concerniente al actor sindical en la Argentina contemporánea. Esta perspectiva teórica, por un lado ha forjado conceptos que se tornaron recurrentes en la ciencia política: partido de base sindical, desindicalización partidaria, partido de base laboral, neo-corporativismo segmentado y revitalización sindical. Por otro lado, la explicación que se ofrece de los términos es muy similar a pesar de que estos remiten a procesos políticos diferentes. Por ello, el artículo

\begin{abstract}
The intention of this work is to analyze the scope and limitations of a neo-institutionalist approach of union actors in contemporary Argentina. This theoretical perspective, on the one hand, has forged concepts that became common in political science: union base party desindicalization, labor base party, segmented neo-corporatism and union revitalization. On the other hand, the explanation of the terms is very similar in spite of the fact that they recount different political processes. For this, the article argues the existence of an explanatory imbalance when the link
\end{abstract}

doi:10.11144/Javeriana.papo20-2.asac

* Artículo de Reflexión. El presente artículo se produjo en el marco de dos proyectos: "Viraje ideológico y emergencia de formas políticas alternativas. Partidos y movimientos de la nueva izquierda en Sudamérica" dirigido por el Dr. Arturo Fernández y "Partidos políticos y sindicatos en Rosario (20032011)" bajo la dirección de Esteban Iglesias.

** Investigador del Consejo Nacional de Investigaciones Científicas (CONICET). Doctor en Ciencia Política y profesor de la Facultad de Ciencia Política y Relaciones Internacionales de la Universidad Nacional de Rosario, Argentina. Se especializa en el estudio de las relaciones entre partidos políticos y movimientos sociales en América Latina. Correo electrónico: estebantatiglesias@yahoo.com.ar. 
argumenta la existencia de un desequilibrio explicativo cuando se aborda el vínculo entre instituciones y actuación sindical. Desde el neo-institucionalismo se observa un énfasis en la incidencia de las instituciones sobre las posibilidades de actuar políticamente de las organizaciones sindicales y no se atiende el modo en el que los actores influyen sobre los marcos institucionales. Esto es relevante en un enfoque teórico que dice priorizar en su análisis 'cómo piensan los actores'.

\section{Palabras clave}

neo-institucionalismo; actor sindical; instituciones; acción política

\section{Cómo citar este artículo:}

Iglesias, E. (2015). La acción sindical en la Argentina contemporánea desde la perspectiva del nuevo institucionalismo. Un análisis de sus alcances y limitaciones. Papel Político, 2O(2), 407-424. http://dx.doi.org/10.11144/ Javeriana.papo20-2.asac is approached between institutions and union action. From neo-institutionalism an emphasis is made on the influence of institutions on the possibilities for political action of unions, and no attention is paid to the way in which actors influence the institutional frames. This is relevant in a theoretical approach that tries to prioritize in its analysis 'how actors think'.

\section{Keywords}

neo-institucionalism; union actors; institutions; political action 


\section{Introducción}

El análisis del actor sindical durante la década del noventa del siglo XX en Argentina ha recibido menor atención, comparándolo con el de partidos políticos y movimientos sociales. Sin embargo, desde la perspectiva del neo-institucionalismo este énfasis no ha decaído. Precisamente, en momentos en los que predominaba la idea de 'inmovilidad' del sindicalismo en un período en el que desde el poder político se intentaba socavar sus bases de sustentación, este enfoque puso atención en su actuación en la arena institucional demostrando que su 'parálisis' no era tal. Lo cierto es que desde la literatura neo-institucionalista se han forjado conceptos para América Latina que hoy circundan la ciencia política casi sin discusión. Así, los términos partido de base sindical, desindicalización partidaria, partido de base laboral, gobierno de base sindical, neocorporativismo segmentado y revitalización sindical ${ }^{1}$ se han vuelto recurrentes.

Llama la atención entonces que la innovación terminológica de los autores neoinstitucionalistas no encuentre una medida correspondiente en los fundamentos teóricos empleados para conceptualizar los procesos políticos. A modo de ejemplo cabe destacar que los términos partido de base sindical y revitalización sindical se explican con argumentos similares: el papel de las instituciones en la sociedad, de allí derivan los motivos que explican la acción y las concepciones políticas de los actores políticos.

Desde el seno del neo-institucionalismo esta vía de entrada analítica se presenta como relevante: "Si efectivamente las instituciones forjan comportamientos mediante la estructura de incentivos que les presentan a los sujetos o como estructuras que dotan de sentido a su accionar, ¿̇por qué deben importar los actores o cómo piensan?” (Acuña \& Chudnosky, 2013, p. 24). Esta pregunta tuvo respuestas teóricas interesantes en Argentina y en menor medida, de investigación empírica en lo que respecta al actor sindical en el período bajo estudio. Sin lugar a dudas, esta dimensión posee relevancia ya que permite develar, al menos en parte, los motivos que imperan en las organizaciones (sindicales) al activarse lógicas políticas de acción diversas en los mismos marcos institucionales. La respuesta de este enfoque ha sido la insistencia en los términos preferencias o intereses y en menor medida, capacidades.

Este trabajo analiza los alcances y las limitaciones de la perspectiva neo-institucionalista en lo que respecta a la actuación del actor sindical en dos períodos de la historia argentina reciente: el período neoliberal y el de la post-convertibilidad. En este lapso temporal las mutaciones implicaron procesos políticos que van desde la denominada desindicalización -ruptura del sindicalismo peronista con el Partido Justicialista-, pasando por las respuestas ante gobiernos que erosionaban su base de sustentación hasta su recomposición política en el plano institucional (revitalización sindical).

\footnotetext{
${ }^{1}$ Excepto este que viene de la literatura anglosajona.
} 
La elección de estos períodos obedece a que facilitan evaluar el tipo de explicación que dio la literatura neo-institucionalista de la acción sindical en momentos históricos en los que se observan diferencias en cuanto a la orientación de las iniciativas estatales y de políticas públicas bajo un mismo signo político: el peronismo, ya sea menemismo o kirchnerismo. De acuerdo con esto y en términos generales, el primer período (1989-2001) corresponde a políticas cuyos resultados han derivado en procesos de exclusión social y política. Mientras que en el segundo período (2001 en adelante) las iniciativas estatales constituyen tentativas orientadas a la recomposición social. Así, las diferencias en el carácter de las iniciativas estatales hacen suponer en principio, que la literatura neo-institucionalista tiene la capacidad de ofrecer diversas dimensiones de análisis de la actuación sindical.

Lo cierto es que entre un período y otro, se modificó de manera significativa, el contexto político y social en el cual se desarrolló la acción sindical. En este sentido y para el accionar político de las organizaciones sindicales, la particularidad del primer período radicó en la identificación del espacio político a ocupar y vinculado a esto, en el dilema de adherir o no a una identidad político-partidaria (el PJ) que impulsaba políticas que perjudicaban sus apoyos políticos, socavando las bases sociales de sus organizaciones. En cambio, el segundo período presenta como marca distintiva una situación de recomposición sindical en el escenario político, lo que ha motivado a la literatura a determinar el grado de protagonismo político de las organizaciones sindicales.

El argumento que se desarrollará en el presente artículo consiste en señalar en este enfoque la existencia de un desbalance explicativo en el vínculo entre instituciones y actores en el mundo sindical. Ciertamente, se enfatiza en la incidencia del plano institucional en la actuación del actor sindical y se muestra escasa sensibilidad interpretativa en la influencia de los actores sobre las reglas formales que rigen las instituciones. Producto de ello, desde esta perspectiva a los marcos institucionales se les adjudican cualidades explicativas que exceden su rango de acción, forzando la categoría de recursos, ya sean políticos o de poder, para abordar la dimensión identitaria ${ }^{2}$ de la acción colectiva de las organizaciones sindicales. En el período neoliberal se señala que estos recursos permitieron preservar el arreglo institucional que se había forjado con el primer peronismo, es decir: 'que no se pierda todo lo conquistado' con su institucionalización. Y en el segundo período, las prerrogativas institucionales permitieron 'el retorno del gigante' al escenario político, explotando las instancias institucionales de concertación política que habilitaron los gobiernos de Néstor Kirchner y Cristina Fernández de Kirchner. Así las cosas, resta una explicación equilibrada que muestre mayor sensibilidad en lo que concierne a la incidencia política del actor en los marcos institucionales.

\footnotetext{
${ }^{2}$ Para una caracterización de la dimensión identitaria de los enfoques sobre acción colectiva se puede consultar a Iglesias (2008) .
} 


\section{El actor sindical en Argentina y el nuevo institucionalismo}

El modelo sindical argentino se estructuró durante las décadas de 1940 y 1950 en el marco de la experiencia constitutiva del peronismo. El arreglo institucional entre Estado y sindicatos asumió las siguientes características: la organización del movimiento sindical por rama de actividad, la personería gremial otorgada por la autoridad estatal, las convenciones colectivas de trabajo y posteriormente, el control por parte de las organizaciones sindicales de las obras sociales. Originalmente, este modelo fue pensado para centralizar la representación de intereses de los trabajadores y que las entidades gremiales no compitiesen entre sí en un contexto en el que las organizaciones forjaban vínculos colectivos de clase (Palomino, 1995). Por característica y funcionamiento, se generaba un modelo sindical centralizado y monopólico en su representación.

Lo cierto es que la institucionalización del poder sindical fue posible en la medida en la que los empresarios toleraron la organización política de los trabajadores en sindicatos. Los sindicatos no cuestionaron más la ganancia y propiedad privada y ambos actores aceptaron el rol regulador del Estado. Finalmente, se destaca que los líderes sindicales contaban con un beneficio adicional: el Estado gestionaba los intereses de la clase trabajadora a través de sus políticas (Benetti, 2012).

Con la institucionalización del actor sindical y los estudios sobre el peronismo en Argentina, la pregunta acerca del modo y el sentido del accionar político en el marco de la problemática de la acción colectiva se convierte en un problema recurrente. En este sentido, los trabajos clásicos que lo abordaron se preguntaban sobre las razones por las cuales la clase obrera y las organizaciones sindicales apoyaban y se identificaban con Perón (Benetti, 2012), colaborando así con la construcción de una nueva identidad política. Con posterioridad, ya en la década del noventa del siglo XX, esta pregunta buscó explicar la "tolerancia popular al ajuste económico" (Navarro, 1995). Así, se analizó la adhesión y apoyo al peronismo, en registro menemista, por parte de la clases populares en el marco de iniciativas estatales de corte neo-conservadora que terminaban perjudicándolos en su situación económica y desarmaban por completo la organización de su vida cotidiana (Sidicaro, 1995; Palermo \& Novaro, 1996; Borçon, 1995; Martucelli \& Svampa, 1997; Quiroga, 2005). Finalmente, en el presente siglo se abrió un nuevo ciclo político que modificó las condiciones políticas en las que se desarrollaba la acción sindical, facilitando su protagonismo político en el plano institucional y en el escenario político. En este marco la pregunta prevaleciente remite al tipo de recomposición política que el sindicalismo experimentó en la Argentina actual.

Así, el interrogante que orienta este trabajo concierne al tipo de explicación que ofreció el enfoque del nuevo institucionalismo sobre el sentido que asumió el accionar político de las organizaciones sindicales en los períodos del neoliberalismo y de la postconvertibilidad en Argentina. En el primer período se señaló que no hubo inactividad por 
parte de las organizaciones sindicales en los procesos de reforma estructural encarados por el menemismo. Y esto se evidenciaba, según los trabajos revisados, en la defensa de las prerrogativas institucionales que emergieron con el primer peronismo y que peligraron con las tentativas reformistas durante el menemismo. En el segundo período la actitud defensiva se modificó por un 'protagonismo político', plasmado nuevamente en las instancias institucionales, convenciones colectivas de trabajo y consejo del salario mínimo.

¿Qué autores retoma la literatura argentina del neo-institucionalismo? En términos generales, cabe destacar que el nuevo institucionalismo en ciencia política involucra una diversidad relevante de corrientes o escuelas de acuerdo al autor que se tome como referencia y los criterios que se apliquen. Por su parte, Guy Peters (1999) plantea la existencia de los siguientes neo-institucionalismos: histórico, elección racional, sociológico, empírico, de representación de intereses e internacional. Por otra parte, Powell y DiMaggio (1999) aluden a un nuevo institucionalismo que remite a la economía institucional, la fenomenología, la acción, elección racional y al planteamiento sociológico al que ellos se inscriben. Finalmente, Hall y Taylor (1999) plantean la existencia de tres neo-institucionalismos: el histórico, el de la elección racional y el sociológico.

Más allá de las tipologías y criterios clasificatorios, lo que distingue al nuevo institucionalismo como enfoque teórico remite al problema de la cambiante relación y los motivos que la explican entre instituciones y actores sociales o individuos y su persistencia o transformación a lo largo del tiempo.

En lo que respecta a los intereses de este trabajo, cabe destacar que los autores que se citan se nutren de las escuelas históricas y sociológicas de acuerdo a la clasificación de Hall y Taylor (1999). En efecto, en Argentina la literatura neo-institucionalista explica los procesos políticos de apoyo/confrontación de las organizaciones sindicales a políticas públicas y partidos en el gobierno priorizando el abordaje de los marcos institucionales en términos de 'reglas' y de su fortaleza o debilidad deriva el comportamiento de los actores. En este sentido, se retoma la conceptualización de North (1995) acerca de las instituciones. North plantea que las instituciones constituyen regularidades y reglas que proporcionan incentivos y desincentivos a los individuos. Lo cierto es que reducen la incertidumbre, proporcionan estructuras confiables y son eficientes para el intercambio económico. Todo esto contribuye a restringir y limitar los procesos de cambio político, reduciendo el abanico de posibilidades para el mismo o encaminándolo. Continuando con el análisis, estos autores consideran que la incidencia institucional en la acción política no se circunscribe a lo que el actor 'debe' hacer sino también a lo que impacta en sus 'preferencias'.

Para articular la problemática del nuevo institucionalismo con la realidad política argentina cabría preguntarse: ¿̇se modificaron las instituciones creándose nuevas, se les asignaron sentidos diferentes por parte del partido que estaba en el gobierno o se modificó el contexto político? Esta pregunta es vital para entender la explicación política 
del neo-institucionalismo. Cierto es que en Argentina, entre el período neo-liberal y el de las post-convertibilidad cambiaron profundamente las condiciones bajo las cuales se desarrolló la acción política de las organizaciones sindicales y no así las características principales del modelo sindical.

Si este diagnóstico tiene veracidad, la literatura neo-institucional en Argentina presenta capacidad explicativa en el período neo-liberal para revalorizar el modo en el que los sindicatos intentaron conservar sus prerrogativas corporativas actuando en el parlamento o a través de la Confederación General del Trabajo. En cambio, en el período de la postconvertibilidad las iniciativas estatales encabezadas por el kirchnerismo son definidas como pro-sindical, lo que termina explicando la vuelta al escenario político del sindicalismo.

\section{Desindicalización partidaria y defensa de las prerrogativas corporativas bajo el signo del neo-liberalismo}

Se registran sus inicios en el último golpe de Estado realizado por las cúpulas militares en 1976, experiencia inscripta en los autoritarismos de nuevo tipo en el Cono Sur. En este sentido, se indica que fue un gobierno que no incluyó prioridades industrialistas en su plan económico desde la década de 1940. Sin embargo, fue con el gobierno de Carlos Saúl Menem que esto que había sido tentativo, constituyó una iniciativa seria, sistemática y global de transformación en el régimen social de acumulación ${ }^{3}$ que se había construido en el período de sustitución de importaciones y promoción del mercado interno.

Ante transformaciones de envergadura, se registraron cambios en diversas dimensiones, las explicaciones van desde la desindicalización partidaria, pasan por el dilema de apoyar o confrontar al partido que gobierna (PJ) y finalizan con la defensa corporativa de los intereses de los líderes sindicales. Así, el presente trabajo focaliza la atención en dos niveles, en la explicación del vínculo entre partido peronista y sindicalismo peronista elaborada por Levitsky (2004) y en la del tipo de apoyo/confrontación hacia el gobierno y sus iniciativas estatales de Murillo (1997) y de Etchemendy y Palermo (1998).

\section{El vínculo partido-sindicatos}

Levitsky (2004) explica la 'veloz y significativa' transformación que se produjo en los vínculos entre partido y sindicatos peronistas haciendo énfasis en el concepto de institucionalización. En este sentido, señala que en términos teóricos "La institucionalización limita el ritmo del cambio organizativo. Cuando las normas y procedimientos están

\footnotetext{
${ }^{3}$ Nun entiende por régimen social de acumulación "[...] al conjunto complejo e históricamente situado de las instituciones y de las prácticas que inciden en el proceso de acumulación del capital, entendiendo a este último como una actividad microeconómica de generación de ganancias y de toma de decisiones de inversión" (Nun, 1995).
} 
institucionalizadas, se forjan en torno de ellos conjuntos de expectativas y de intereses estables" (Levistky, 2004). Esta forma de entender la institucionalización partidaria hace que Levitsky considere que, por definición, las relaciones institucionalizadas entre organizaciones tengan un carácter 'estático', y a su vez, que no cambien a la misma velocidad de otros tipos de recursos como las 'preferencias' y la 'distribución del poder'.

Desde esta perspectiva teórica, el vínculo entre organizaciones se considera como un conjunto de normas y procedimientos que permiten un conjunto de interacciones -apoyo e influencia-entre el partido y los sindicatos. Por ello Levitsky se concentra en los mecanismos de participación sindical en el partido. En este sentido Levitsky argumenta que:

[...] la notable transformación del PJ fue posible debido a la escasa institucionalización de los vínculos entre el partido y los sindicatos. Estos últimos tuvieron siempre un importante papel en el peronismo, pero las reglas del juego que determinaban su participación estaban mal definidas y eran demasiado fluidas y cuestionadas. Esto hizo que los vínculos entre el partido y los sindicatos fueran vulnerables a las variaciones producidas dentro del peronismo en la distribución del poder y las preferencias como consecuencia de la transición democrática iniciada en 1983. (2004)

Este proceso provocó que los mecanismos tradicionales de participación sindical al interior del partido se modificaran y que a su vez, produjeran un cambio en la base social y en su identidad, pasando de ser un partido de 'base sindical' a ser uno 'clientelista' fundado en el patronazgo.

Destruidos los canales de participación sindical, se modificó el poder ejercido por el sindicalismo en la orientación política del partido. Ni las 62 organizaciones peronistas ni los sindicatos emblemáticos condujeron el partido, fueron más bien los caudillos políticos que dominaban determinado territorio (Levistky, 2004, p. 10). El cargo político se constituyó precisamente en una de las principales fuentes de poder -organizado en torno al poder territorial-y de financiamiento, su pilar fue el acceso que tenía el caudillo político a los recursos estatales. Finalmente, Levitsky concluye entonces que

Estos cambios beneficiaron al partido en dos aspectos: en primer lugar, le permitieron apelar al creciente electorado de clase media sin divorciarse de los grupos de apoyo urbanos de clase obrera y clase baja; en segundo lugar, a partir de 1989 incrementaron la capacidad del gobierno de Menem para poner en práctica reformas orientadas al mercado. (2004)

En lo que respecta al vínculo entre partido y sindicatos peronistas, una dimensión institucional débil se erige en el principal factor explicativo acerca de la pérdida de poder del sindicalismo peronista al interior de la esfera partidaria y asimismo, explica las 
transformaciones en los principios que identificaban al peronismo hasta ese entonces, sin perder su caudal electoral.

\section{El sindicalismo peronista ante los gobiernos de Carlos Menem}

Murillo (2005) analiza las respuestas sindicales frente a las instituciones estatales en un contexto de profundos cambios -orientación neoliberal- que colocó a las organizaciones sindicales en el dilema de apoyar o confrontar al partido que estaba al frente del gobierno, PJ, organización con la que tenían afinidad política y que promovía cambios que afectaban sus patrones históricos de acción frente al Estado ${ }^{4}$.

Murillo sostiene que los factores que explican las interacciones entre partidos y sindicatos, en particular la lealtad o ruptura de los trabajadores con los partidos tradicionalmente aliados (PJ-sindicalismo peronista) son: “[...] los incentivos creados por las lealtades partidarias, la competencia entre los líderes sindicales y la competencia entre los sindicatos [...]” (Murillo, 2005, p. 11). Es así que "[...], el sindicalismo y los partidos de base laboral hicieron un intercambio: apoyo de los trabajadores a cambio del compromiso partidario de brindar a los sindicatos acceso al Estado" (Murillo, 2005, p. 12).

En cuanto a la respuesta sindical, se señala la existencia de tres tipos de reacciones frente a gobiernos que implementan 'reformas de mercado': de 'resistencia', de ‘subordinación' y de 'supervivencia organizativa'. Esta última es la que presenta mayor novedad para Murillo:

Estas reacciones sindicales resultan de diferencias en la distribución de recursos sindicales (políticos, industriales y organizativos). La distribución de dichos recursos, en conjunto con los legados institucionales de las organizaciones sindicales, contribuye a explicar las diferentes reacciones de las organizaciones sindicales frente al desafío que representan las reformas estructurales implementadas por el peronismo. Incluso, la innovadora respuesta sindical que compensa la erosión de los recursos industriales y políticos con actividades empresarias (supervivencia organizativa) está relacionada con un legado de recursos organizativos desarrollado a lo largo de varias décadas. (Murillo, 1997)

La particularidad que presentó este tipo de respuesta consistió en que a los dirigentes peronistas les permitió influir sobre las reformas propuestas por el gobierno nacional. Finalmente, Murillo señala las posibilidades de acción política de la estrategia de 'supervivencia organizativa' frente a las otras:

\footnotetext{
${ }^{4}$ Habría que agregar, ciertamente, que en Argentina estos cambios fueron implementados por el $\mathrm{PJ}$, fuerza política que institucionalizó el poder sindical a mitad de siglo XX.
} 
La estrategia de "supervivencia organizativa" en la Argentina aumenta las posibilidades de acción que confrontan los sindicatos frente a la redefinición de su relación con el Estado. No obstante, las condiciones creadas por las reformas estructurales implementadas por partidos populistas vinculados con el sindicalismo no son suficientes para inducir a los sindicatos a esta estrategia. La emergencia de la "supervivencia organizativa" precisa del legado de recursos organizativos que proveen a los sindicatos involucrados con fondos y experiencia gerencial necesarios para iniciar el proceso de mercantilización del corporativismo. (Murillo, 1997, p. 441)

\section{La modificación en la legislación laboral}

Etchemendy y Palermo (1998) analizan el proceso de formulación de la reforma laboral considerada como una de las reformas de mercado que encaró el primer gobierno de Carlos Menem (1989-1995). El interés de esto radica en que a diferencia de otro tipo de reformas -de liberalización comercial, privatizaciones, etc.- la reforma laboral es particularmente importante, ya que impacta en la clase trabajadora de forma homogénea y no en sectores productivos puntuales.

¿Cómo se dio este proceso particular en un contexto de pérdida de poder del actor sindical? Esta pregunta es relevante ya que Etchemendy y Palermo señalan que las transformaciones más significativas en este tema se realizaron sobre el final del primer gobierno de Carlos Menem cuando el Ministro de Trabajo era Caro Figueroa. De acuerdo con esto, destacan que fue posible distinguir dos momentos: el primero de 1989 a 1993 en el que existió una escasa producción legislativa y el segundo de 1994-1995, en el que esta se extiende y asume consistencia. ¿Qué razones han operado en esto?

Las instituciones implican distribución de poder ya que congelan relaciones de fuerza entre los actores sociopolíticos (Knight, 1992). A través de la legislación laboral se libra una batalla esencialmente política y los momentos de cambio en las instituciones laborales significan para las organizaciones de interés y el gobierno victorias, derrotas y oportunidades para buscar apoyos. (Collier \& Collier, 1979, ctd en Etchemendy \& Palermo, 1998, p. 563)

Los autores argumentan que en los primeros años el ‘bloqueo legislativo’ fue la causa principal que impidió el avance que el gobierno nacional pretendía para la reforma laboral. Se constata la aprobación de la Ley de Empleo, una reforma a la Ley de Accidentes de Trabajo y reforma de la Negociación Colectiva para trabajadores estatales. Hasta 1994 estas iniciativas no habían impactado en la regulación de la fuerza de trabajo pues continuaba prevaleciendo en el empleo asalariado el contrato por tiempo indeterminado. Sin embargo, como esto afectaba la forma tradicional en que se organizaban los sindicatos, en este período la moneda de cambio del gobierno, fue la promulgación de la ley 24.070 por la cual el Estado se hacía cargo de la deuda que tenían los sindicatos 
con las obras sociales. De todas maneras, lo más relevante para los autores radicó en que el bloqueo legislativo se pudo observar en el accionar de los diputados de extracción sindical en la Comisión de Legislación del Trabajo: "La comisión fue un arma fundamental que el sindicalismo peronista utilizó tanto para negociar como para congelar las iniciativas cuando la negociación se estancaba" (Etchemendy \& Palermo, 1998, p. 577).

En 1994 la estrategia gubernamental se modificó apelando a la concertación con los actores sociales. En efecto, este cambio de estrategia lo encabezó el nuevo Ministro de Trabajo, Caro Figueroa, y fue denominada por Etchemendy y Palermo (1998) como 'concertación tripartita'. Así fue como el gobierno llamó a la CGT y a la UIA para avanzar en los proyectos de reforma laboral antes de enviarlos al Congreso. Para los autores fue un 'proceso organizado de concertación' que dio como resultado la firma de un 'Acuerdo Marco para el Empleo, la Productividad y la Equidad Social' entre los actores sociopolíticos. Así el gobierno nacional, en un breve lapso de tiempo concretó: la reforma laboral para PyMES, nueva flexibilización en las modalidades de contratación, reforma integral del régimen de accidentes de trabajo, nueva ley de quiebras, ley de mediación para disminuir la litigiosidad laboral y algunas reformas en el rubro de obras sociales.

Para Etchemendy y Palermo (1998) esta 'concertación' presenta rasgos novedosos. En un contexto de franca retirada del arreglo 'neo-corporativista', se promueve la 'representación funcional', instancia que se diferencia de medidas 'decisionistas' y además, de concebir al Estado en una arena distinta a aquella en donde los grupos de interés presionan para obtener beneficios particulares. En efecto, la autoridad estatal lauda entre las partes, representantes del capital, UIA y representantes del trabajo, CGT. Finalmente, los autores destacan los beneficios que obtuvieron los interesados: “[...] ningún actor vio cristalizadas sus propuestas de máxima, pero todos lograron -o salvaron- determinadas prerrogativas” (Etchemendy \& Palermo, 1998, p. 584).

Para Levitsky, Murillo, Etchemendy y Palermo la dimensión institucional constituye el principal referente explicativo del accionar sindical. En el primero, la escasa institucionalización del vínculo partido-sindicatos, posibilitó cambios en la dimensión identitaria generando la aceptación del 'credo neoliberal'. En el segundo se presenta como 'novedad' frente a las otras una respuesta sindical denominada supervivencia organizativa, ya que aumenta las posibilidades de acción de los sindicatos si no se confronta con el Estado y se pretende preservar las prerrogativas institucionales en la representación de intereses. Finalmente, los terceros muestran mayor sensibilidad al grado de incidencia de los actores sobre la formulación de la política pública.

\section{Gobierno pro-sindical y el regreso (inesperado) del 'gigante' en el período de la post-convertibilidad}

En este período la literatura neo-institucional se encuentra particularmente preocupada por determinar cuáles fueron los factores que incidieron en el 'renovado' e 'inesperado' 
protagonismo político del actor sindical así como también en qué ámbito se desarrolló durante el presente siglo. El eje de la discusión cambia, dejando de lado el interrogante acerca de lo que hizo el sindicalismo durante el neoliberalismo con el propósito de evaluar la naturaleza de la recomposición política del actor sindical. Los términos gobierno pro-sindical y revitalización sindical dan cuenta de estos procesos políticos.

Sin embargo, lo primero que hay que explicar aparentemente, es lo 'inesperado’ del retorno del actor sindical o del 'gigante invertebrado', como lo denominó Juan Carlos Torre (2012), al escenario político. Así se indica que "Enfocados en el caso argentino pos 2003, el resurgimiento sindical no puede entenderse sin señalar dos factores clave: la herencia institucional y el rol del gobierno" (Etchmendy, 2013, p. 297). De acuerdo con esto, el primer factor remite a las características del modelo sindical argentino mientras que el segundo refiere al cambio en la política macroeconómica que ejecutó el kirchnerismo desde que asumió el gobierno nacional. La combinación de lo institucional con lo político-económico ofreció el formidable trampolín que catapultó al actor sindical a un nuevo protagonismo político. Según Etchemendy, esta situación se consagró en una 'doble alianza' con la CGT y de la fracción mayoritaria con la CTA, la CTERA. En este contexto, el autor entiende que el papel del sindicalismo es más que nunca "un agente de gobernabilidad socioeconómica” y no un "aparato político-electoral.”

Etchemendy y Colliers (2008) ${ }^{5}$ plantean una confluencia de factores de largo plazo en su explicación. En este sentido, indican que el nuevo protagonismo político del actor sindical se observa claramente en el regreso del conflicto laboral en su formato de huelga y en el plano institucional en la negociación colectiva. En este periodo ambas dimensiones funcionan de modo complementario, destacando que el poder de movilización de los sindicatos ha incrementado y que la instancia de la huelga constituye un recurso poderoso que se activa y se desactiva al compás de las negociaciones salariales. Así, concluida la negociación paritaria el llamado a la huelga por parte del sindicato se apacigua. Además,

[...] a diferencia de otros casos de reforma neoliberal profunda, la desindustrialización en Argentina no supuso un viraje de la producción hacia sectores que tradicionalmente no habían sido sindicalizados o eran difíciles de organizar (tales como las industrias intensivas en recursos naturales en Chile o la producción de tipo maquila en México). Por el contrario, los sectores que han crecido en el contexto de la liberalización del mercado y que conforman la nueva vanguardia del sindicalismo argentino, como los de alimentos, transporte y petróleo

\footnotetext{
${ }^{5}$ En este artículo los autores se proponen describir el resurgimiento de sindicatos en dos áreas: 1) el conflicto laboral y 2) la negociación colectiva. También analizan el resurgimiento de los sindicatos como resultado de factores de largo plazo (preservación organizacional y realineamientos sectoriales) y de corto plazo (un gobierno favorable a los intereses sindicales y cambios en el mercado de trabajo).
} 
privado, a pesar de haber sido relativamente moderados durante la ISI, poseían altas tasas de sindicalización y engendraron tradicionales prácticas de negociación colectiva y militancia. Por lo tanto, pudieron activarse una vez que las reformas de mercado favorecieron su expansión. En segundo lugar, los sindicatos tradicionales fueron capaces de lograr en el curso de las reformas de la década de 1990 concesiones institucionales que contribuyeron a conservar lo que Wright (2000) denomina el poder asociacional de los sindicatos, específicamente, un marco para las negociaciones salariales centralizadas, el mantenimiento del monopolio a nivel de planta y la administración de las obras sociales para los trabajadores. Estos recursos institucionales pudieron ser utilizados en el contexto inmediato de la recuperación económica y de un gobierno más benevolente. (Etchemendy \& Colliers, 2008, p. 150)

El resultado de investigación que presentan Etchemendy y Colliers remite al tipo de arreglo institucional entre Estado y sindicatos que se expresa en un 'neo-corporativismo segmentado', es decir, en una modalidad que restablece el poder a los líderes sindicales en el diálogo político con el gobierno nacional.

En el marco de las mismas preocupaciones, Senén y Medwid (2007) se proponen buscar las razones que explican la revitalización del conflicto laboral y si la misma se debe a las posibilidades que brinda la nueva coyuntura económica, política e institucional o a las características propias de los actores sindicales y sus estrategias para aprovechar, resistir o adaptarse a las exigencias del nuevo contexto: "Por otra parte, nos interesa particularmente conocer si efectivamente es la nueva coyuntura o son las características de los actores -entendidas por su capacidad de presión- las que influyen en el surgimiento, modalidad y resultados de los conflictos" (Senén \& Medwid, 2007, p. 209).

Senén complejiza la explicación neo-institucional instalando el término revitalización sindical ${ }^{6}$. Esto es, en términos generales, explicar el renovado protagonismo político del actor sindical en Argentina en el plano institucional, más específicamente, en el plano de la negociación colectiva7. Así, se pregunta:

[...] el nuevo escenario económico político y social que se viene registrando en Argentina donde se constata un renovado protagonismo sindical ciesta revitalización es producto de

\footnotetext{
${ }^{6}$ Alude a "[...] tres dimensiones: aumento de la cantidad de trabajadores afiliados, crecimiento del número de acuerdos y convenios de negociación colectiva y traslado del conflicto social al conflicto laboral. De esta manera, el sindicalismo recobró el rol protagónico que en buena medida había perdido durante la década de reformas neoliberales en los noventa" (Senén, 2008, p. 13) 7 Según Senén "[...] los datos que evidencian la posibilidad de conceptualizar este proceso como revitalización no están dirigidos a aumentar la cantidad de afiliados -como sostiene gran parte de la literatura- sino a fortalecer su posición institucional a través de la coalición política con el gobierno actual. Esto sería observable en particular cuando se analiza la negociación colectiva" (Senén, 2011, p. 51).
} 
acciones transformadoras propias del actor sindical por renovarse o es una reacción del sindicato ante los cambios del contexto? (Senén, 2011, p. 51)

La evidencia empírica que reconstruye la autora involucra tres niveles: la tasa de afiliación sindical, la negociación colectiva y la conflictividad laboral. Ciertamente, lo más interesante se encuentra en el plano de la negociación colectiva, señalando que no solo aumentó la cantidad de acuerdos firmados sino que a su vez se modificaron sus contenidos. Así, señala que:

En la actualidad [entre 2001 y 2008] la negociación salarial es el contenido que predomina. La negociación colectiva se caracteriza por el predominio de las cláusulas salariales y adquiere un rol central como instituto laboral de determinación salarial y como mecanismo de diálogo social para la resolución de la puja distributiva. Entre 2002 y 2008, todos los convenios colectivos de mayor cobertura tuvieron un incremento salarial por impulso de la política oficial o por decisión de los actores sociales en la negociación colectiva. (Senén, 2011, p. 55)

Finalmente Senén y Del Bono (2013) destacan lo que sería la inspiración principal de la literatura internacional que se observa en Argentina sobre revitalización sindical. Así, las mejores condiciones económicas y políticas favorecieron,

[...] notablemente el resurgimiento de un actor central de las relaciones laborales como son los sindicatos. Este se ha vuelto visible en dos planos principales: la recuperación del dinamismo de la negociación colectiva y en el aumento del conflicto laboral, como su contracara. (Senén \& Del Bono, 2013, p. 8)

\section{Conclusiones: hallazgos y limitaciones de la perspectiva teórica}

Este trabajo se propuso analizar los alcances y limitaciones del enfoque neo-institucional sobre la actuación sindical en dos períodos democráticos de la Argentina contemporánea. El foco de interés radicó en analizar las interacciones entre instituciones y actores para observar la mutua incidencia, entendiendo que desde este enfoque los actores son relevantes.

En la literatura revisada lo que predomina es el énfasis en las posibilidades y restricciones que brindan los marcos institucionales sobre el actor sindical. Queda poco explotado el modo en que los actores inciden en los marcos institucionales. Así, en el primer período, bajo el signo del neoliberalismo, se señaló que el accionar político del sindicalismo no se vinculó mayormente con su participación en el conflicto social sino con intentar detener lo que pudo ser una modificación global del modelo sindical que se forjó con el primer peronismo. Así es como se destaca que en un contexto adverso para el actor sindical su dinámica estuvo circunscripta a defender 'intereses corporativos'. 
Los recursos políticos, ideológicos y económicos desplegados por el sindicalismo, principalmente peronista, en el plano institucional -en el congreso o negociando desde la CGT con los ministros del gobierno nacional- se pusieron a disposición de reformas orientadas a modificar la gravitación política del sindicalismo en el régimen político.

Desde esta perspectiva la dimensión institucional también explica la tolerancia a los cambios sucedidos en la dimensión identitaria de la organización partidaria del Partido Justicialista. En efecto, Levitsky señala que la escasa institucionalidad de los vínculos entre partido y organización sindical explica la marginación política del sindicalismo al interior de la esfera partidaria. El pasaje de partido de 'base sindical' a 'partido clientelista' describe claramente este proceso.

En el segundo período, el de la post-convertibilidad económica, se modificaron las condiciones políticas y económicas en las que se desarrollaba anteriormente la acción sindical. Esto provocó una recomposición política del sindicalismo, lo que se observó en tres dimensiones: el aumento de la tasa de afiliación, el traslado de la protesta social hacia el reclamo laboral y la negociación colectiva, en cantidad de acuerdos y en sus contenidos. De estos tres componentes el que ha sido subrayado principalmente es el de la negociación colectiva. Esta dimensión institucional es la que explica la dinámica de las otras, principalmente la del conflicto laboral. Las huelgas se detienen cuando termina la negociación paritaria y se reactivan al año siguiente. La dimensión subjetiva del actor en este período presenta menores preocupaciones que el período anterior ya que se trata de un partido en el gobierno que implementa políticas afines con las del sindicalismo. En efecto, se trata de un gobierno 'pro-sindical' o de 'base laboral'.

Esta perspectiva informa mayormente, sobre las posibilidades y restricciones de la acción política del actor sindical, lo que nos indica su capacidad de adaptación, ya sea a los 'malos' o 'buenos' tiempos. Sin embargo, no explota el reverso de la trama: el modo en que el actor descarga su capacidad política sobre las instituciones. Este terreno debería 'importar más' en un enfoque que deposita en los 'actores' su vía de entrada explicativa sobre los vínculos entre política y sociedad.

\section{Referencias}

Acuña, C., \& Chudnosky, M. (2013). ¿Cuánto importan las instituciones? Buenos Aires: OSDE.

Benetti, G. (2012). Estado y sindicatos en la Argentina en tiempos de neo-liberalismo (1989-1999). Tesis de doctorado no publicada, Universidad Nacional de Rosario. Facultad de Ciencia Política y RRII. Rosario.

Borón, A. (1995). El experimento neoliberal de Carlos Saúl Menem. En Hora, R., \& Trímboli, J. (Comps.). Peronismo y menemismo (pp.11-46). Buenos Aires: El Cielo por Asalto. 
Di Tella, T. (1985). Sociología de los procesos políticos. Buenos Aires: Grupo Editorial Latinoamericano.

Doyon, L. (1989). Conflictos obreros durante el régimen peronista (1946-1955). En Torre, J. C. Torre (Comps.). La formación del sindicalismo peronista (pp. 221-263). Buenos Aires: Legasa.

Etchmendy, S. (2013). La “doble alianza” gobierno-sindicatos en el kirchnerismo (20032012). En Acuña, C. (Comp.). ¿Cuánto importan las instituciones? (pp. 291-324) Buenos Aires: Siglo XXI.

Etchemendy, S., \& Colliers, R. (2008). Golpeados pero de pie. Surgimiento sindical y neocorporativismo segmentado en Argentina (2003-2007). Postdata, (13), 145-192.

Etchemendy, S., \& Palermo, V. (1998, enero-marzo). Conflicto y concertación. Gobierno, Congreso y organizaciones de interés en la reforma laboral del primer gobierno de Menem (1989/1995). Desarrollo Económico, 37(148), 459-490.

Germani, G. (1962). Política y sociedad en una época de transición. Buenos Aires: Paidós.

Hall, P., \& Taylor, R. (1999). La ciencia política y los tres nuevos institucionalismos. Revista Conmemorativa del Colegio Nacional de Ciencias Políticas y Administración Pública, dossier, 15-53.

Horowitz, J. (1989). El impacto de las tradiciones sindicales anteriores a 1943 en el peronismo. En Torre, J. C. (Comp.). La formación del sindicalismo peronista (pp. 99-118). Buenos Aires: Legasa.

Iglesias, E. (2008). Política y protesta. Visiones comparadas de la acción colectiva. En Fernández, A., \& Lesgart, C. (Comp.). La democracia en América Latina. Partidos políticos y movimientos sociales (pp. 149-170). Rosario: Homo Sapiens.

Laclau, E. (1978). Política e ideología en la teoría marxista. Capitalismo, fascismo y populismo. Madrid: Siglo XXI.

Laclau, E., \& Mouffe, C. (1987). Hegemonía y estrategia socialista. Hacia una radicalización de la democracia. Buenos Aires: Fondo de Cultura Económica.

Levitsky, S. (2004). Del sindicalismo al clientelismo: la transformación de los vínculos partido-sindicatos en el peronismo, 1983-1999. Desarrollo Económico, 44(173), 3-32.

Levitsky, S. (2005). Transformación del Justicialismo: Del Partido Sindical al Partido Clientelista. Buenos Aires: Siglo XXI.

Little, W. (1989). La organización obrera y el Estado peronista. En Torre, J. C. (Comp.). La formación del sindicalismo peronista (pp. 265-320). Buenos Aires: Legasa. 
Martucelli, D., \& Svampa, M. (1997). La plaza vacía. Las transformaciones del peronismo. Buenos Aires: Losada.

Murillo, M. V. (1997). La adaptación del sindicalismo argentino a las reformas del mercado en la primera presidencia de Menem. Desarrollo Económico, 37(147), 419-460.

Murillo, M. V. (2005). Sindicalismo, coaliciones partidarias y reformas de mercado en América latina. España: Siglo XXI.

Murmis, M., \& Portantiero, J. C. (1971). Estudios sobre los orígenes del peronismo. México, España, Argentina y Colombia: Siglo XXI.

Navarro, M. (1995). Democracia y Reformas estructurales: explicaciones de la tolerancia popular al ajuste económico. Desarrollo Económico, 35(139), 443-466.

North, D. (1995). Instituciones, cambio institucional y desempeño económico. México: Fondo de Cultura Económica.

Nun, J. (1995). Populismo, representación y menemismo. En Hora, R., \& Trímboli, J. (Comps.). Peronismo y menemismo. Avatares del populismo en América Latina (pp. 67-100). Buenos Aires: El Cielo por Asalto.

Palomino, H. (1995). Quiebres y rupturas de la acción sindical: un panorama desde el presente sobre la evolución del movimiento sindical en Argentina. En Acuña, C. (Comp.). La nueva matriz política argentina (pp. 203-229). Buenos Aires: Nueva Visión.

Palermo, V., \& Novaro, M. (1996). Política y poder en el gobierno de Menem. Buenos Aires: Norma.

Peters, G. (1999). El nuevo institucionalismo. Teoría institucional en ciencia política. Barcelona: Gedisa.

Powell, W., \& Dimaggio, P. (1999). El nuevo institucionalismo en el análisis organizacional. México: Fondo de Cultura Económica.

Quiroga, H. (2005). La Argentina en emergencia permanente. Buenos Aires: Edhasa.

Senén, C. (2008). La expansión de la afiliación sindical: análisis del módulo de relaciones laboral EIL, Nro. 8. Argentina: Ministerio de Trabajo, Seguridad y Empleo.

Senén, C. (2011, julio-septiembre). La revitalización sindical en Argentina durante los Kirchner. Revista Trabajo, (8), 39-63.

Senén, C., \& Del Bono, A. (2013). La revitalización sindical en Argentina: alcances y perspectivas. Buenos Aires: Prometeo. 
Senén, C., \& Medwid, B. (2007). Capacidad de presión sindical y conflictividad laboral en la Argentina post-devaluación: el caso del sector aceitero. En Fernández, A. (Comp.). Estado y sindicatos en perspectiva latinoamericana (pp. 207-233). Buenos Aires: Prometeo.

Sidicaro, R. (1995). Poder político, liberalismo económico y sectores populares en la argentina 1989-1995. En Hora, R., \& Trímboli, J. (Comps.). Peronismo y menemismo (pp. 119-156). Buenos Aires: El Cielo por Asalto.

Torre, J. C. (2012). Ensayos sobre el movimiento obrero y peronismo. Buenos Aires: Siglo XXI.

Waisman, C. (1980). Modernización y legitimación: la incorporación de la clase obrera al sistema político. España: Centro de Investigaciones Sociológicas. 